\title{
POSSE, PROPRIEDADE E TERRITORIALIDADES RIVAIS: entre os conceitos jurídicos e os saberes locais
}

\section{André Viana da Cruz*}

RESUMO: O presente artigo aborda a temática da ocupação da terra entre sesmarias, posses e o discurso proprietário, bem como o percurso histórico-jurídico da privatização da terra e a cristalização no Código Civil de 1916 do direito de propriedade moderna, apresentando a equivocada valoração jurídica do uso comum. A formulação enfrenta a consagração do domínio útil como pedra angular da propriedade moderna, que, ainda assim, guarda reminiscências de diferentes formas de uso pré-modernos. Destaca-se a existência de territorialidades rivais às formas reconhecidas pelo direito proprietário, demonstrando que tais diferentes formas de apropriação, desenvolvidas através do saber local, além de não serem reconhecidas, foram combatidas e invisibilizadas pelo modelo implantado, através da figura do Estado e do monismo jurídico consolidados na modernidade.

Palavras-chave: posse; propriedade; discurso proprietário; saber local; uso comum; territorialidades.

\section{POSSESSION, PROPERTY AND RIVAL TERRITORIALITIES: between legal concepts and local knowledge}

\begin{abstract}
The present article deals with the land occupation between land use, land ownership and owner discourse, as well as the historical and juridical course of the privatization of land and the crystallization of the 1916 Civil Code of modern property rights, presenting the mistaken valuation Common use. The formulation faces the consecration of the useful domain as the cornerstone of modern property, yet reminiscent of different premodern forms of use. It emphasizes the existence of rival territorialities to the forms recognized by the proprietary right, demonstrating that these different forms of appropriation, developed through local knowledge, besides not being recognized, were combated and invisibilizadas by the model implanted, through the figure of the State and of the Legal monism consolidated in modernity.
\end{abstract}

Keywords: possession; property; proprietary speech; local knowledge; common use; territorialities.

\section{Introdução}

\footnotetext{
* Mestre em Direito Cooperativo e Cidadania e Doutor em Direito das Relações Sociais, pelo Programa de Pósgraduação em Direito da Universidade Federal do Paraná; Pós doutorando no Programa de Pós-graduação em Direito Agrário da Universidade Federal de Goiás; professor de Direito Civil. Advogado.
}

Revista de Sociologia, Antropologia e Cultura Jurídica | e-ISSN: 2526-0251 | Maranhão | v. 3 | n. 2 | p. 18 - 44 | Jul/Dez. 2017. 
A noção de propriedade privada nos remete a uma individualização no uso das coisas. Com raras exceções situadas no campo do condomínio, a ideia de uso exclusivo prepondera. Todavia, situações concretas demonstram que a apropriação coletiva persiste e, mais, resiste ao modelo proprietário proposto com a modernidade ${ }^{1}$.

Para o direito moderno, bens são as coisas apropriáveis, valoráveis e passíveis de livre circulação no mercado. Portanto, a noção de bem está diretamente ligada à economicidade e à apropriação. A ideia de apropriação nos remete ao conceito de propriedade, cuja história da garantia contempla a própria história do Direito $^{2}$ e "Pode-se, lançando um olhar sobre a modernidade ocidental, enxergar a construção do discurso proprietário: um determinado modelo de propriedade torna-se em princípio do direito moderno, por conta do centralismo ocupado pelo direito privado do oitocentos”3.

Pela lógica do sistema jurídico proprietário todo direito tem um titular, uma pessoa, um sujeito de direito, individual ainda que ficção, sendo sempre necessário que se tenha um bem, uma coisa, um objeto. Com o advento da modernidade, tudo o que fosse coletivo e não pudesse ser entendido como estatal, não é juridicamente relevante. "Tudo o que não pudesse ser materializado em patrimônio e não pudesse ter um valor ainda que simbólico, também estava fora do direito" (SOUZA FILHO: 2005. p. 168.), pois, conforme ensina Pietro Barcelona, o conceito de propriedade privada, como forma geral de disponibilidade das coisas, se converte em norma de funcionamento de toda a sociedade e das relações humanas (BARCELONA: 1996. p. 20).

Com titular sempre identificado e objeto conhecido e avaliável economicamente, verificase a valoração jurídica para o direito resolver as pendências, o que normalmente se verifica em perdas e danos. Tal regra também é adotada para direitos intangíveis, como a identidade cultural ${ }^{4}$.

\footnotetext{
${ }^{1}$ Entendido como modernidade o período da história ocidental que começa depois do Renascimento, quando se adota uma perspectiva antropocêntrica, separando o corpo da alma, que estabelece centralidade na razão e certeza nas representações. No campo da apropriação das coisas vemos consagrado um modelo econômico que sustenta a construção patrimonialista: o que não demanda uma possibilidade de troca não é reconhecido.

2 "A história do Direito é, em boa medida, a história da garantia da propriedade”. (FACHIN, Luiz Edson. Teoria Crítica do Direito Civil. Rio de Janeiro: Renovar, 2000. p. 71)

${ }^{3}$ CORTIANO JÚNIOR, Eroulths. O Discurso Proprietário e suas Rupturas: Prospectiva e Perspectivas do Ensino do Direito de Propriedade. Curitiba, 2001. Tese (Doutorado em Direito) - Setor de Ciências Jurídicas, Universidade Federal do Paraná. f. 3.

4 "A identidade é um princípio de coesão interiorizado por uma pessoa ou um grupo. Permite-lhes reconhecerem-se e serem reconhecidos. A identidade consiste num conjunto de características partilhadas pelos membros do grupo, que
} 
“A vida de cada um passa a ser valorada patrimonialmente, o imaterial se materializa no valor de troca, ainda que trocar não se quer” (SOUZA FILHO: 2005. p. 168.).

Há que se discutir, também, a teoria objetiva da posse civil, pois os elementos simbólicos que estabelecem a identidade territorial ultrapassam a noção de exteriorização dos poderes inerentes à propriedade (modernamente construídos). Existem elementos objetivos no território, mas os mesmos transcendem os limites materiais identificáveis pelos parâmetros da sociedade envolvente.

A noção de território permeia a discussão, trazendo elementos simbólicos não alcançados pela mera exteriorização dos poderes inerentes a propriedade. A compreensão da territorialidade pressupõe um diálogo intercultural ${ }^{5}$ que reconheça os processos contínuos de produção de significados e significantes. A pluralidade cultural implica na possibilidade da pluralidade jurídica e é nesse campo que se situa a grande questão a ser resolvida pela antropologia, que, assim, requer uma abordagem para além do evolucionismo unilinear.

O direito moderno, contemplando a supremacia a lei, cinde os sujeitos dos objetos, mas tal dicotomia não é unânime a todos os saberes. Os conhecimentos dos povos tradicionais demonstram um modo de pensar o mundo integrando a realidade social, material e mística.

O presente artigo aborda a temática da ocupação da terra entre sesmarias, posses e o discurso proprietário, bem como o percurso histórico-jurídico da privatização da terra e a cristalização no Código Civil de 1916 do direito de propriedade moderna, apresentando a equivocada valoração jurídica do uso comum. A formulação enfrenta a consagração do domínio útil como pedra angular da propriedade moderna, que, ainda assim, guarda reminiscências de diferentes formas de uso pré-modernos. Destaca-se a existência de territorialidades rivais às formas reconhecidas pelo direito proprietário, demonstrando que tais diferentes formas de

permitem um processo de identificação das pessoas no interior do grupo e de diferenciação em relação aos outros grupos” (LABURTHE-TOLRA, Philippe; WARNIER, Jean-Pierre. Etnologia-Antropologia. Trad. Anna Hartmann Cavalcanti; revisão da trad., org. literária e editoração Jaime A. Clasen; revisão técnica Antônio Carlos de Souza Lima. Petrópolis: Vozes, 1997. p. 409).

${ }^{5}$ A interculturalidade nos conduz a uma contextualização do pensamento e do conhecimento no marco da pluralidade e da diversidade cultural e histórica do mundo. "A interculturalidade comporta, pois, como ponto de partida um elemento importante e radical de crítica e de protesto frente ao império de um universo cognitivo dominante, hegemônico e monista, o qual tem servido historicamente de obstáculo para escutar a quem também tem algo diferente a dizer.”DULCE, María José Farínas. La tensión del “pluralismo" desde la perspectiva filosófica intercultural. In Derechos y Libertades - Revista del Instituto Bartolomé de Las Casas. Año VIII. Enero/Diciembre. Número 12. Universidad Carlos III de Madrid. Boletín Oficial del Estado. 2003, p. 196. 
apropriação além de não serem reconhecidas, foram combatidas e invisibilizadas pelo modelo implantado, através da figura do Estado e do monismo jurídico consolidados na modernidade.

A ocupação da terra é juridicamente garantida ao longo do século XIX pelos institutos das sesmarias, posses e propriedade. O percurso histórico desses institutos demonstra que, na modernidade individualista, a ajuda mútua remanesceu e foi instrumentalizada para buscar resolver as contradições do capitalismo. Apesar disso, a desvalorização jurídica do uso comum da terra demonstra que o direito positivo brasileiro abarca o fenômeno da comunhão apenas marginalmente, previsto no regime de bens do casamento e na figura do condomínio de origem romana. O direito de propriedade se distancia do real e é hostil ao acolhimento das experiências, nas quais se pode compor uma nova dinâmica de uso da terra. É nessa perspectiva que o uso comum da terra se apresenta como uma territorialidade rival à outra constituída e reconhecida pelo direito proprietário.

\section{Lei de Terras no discurso proprietário prevalente}

O instituto das sesmarias foi criado em Portugal, no ano de 1375, por Dom Fernando para solucionar uma crise de abastecimento de alimentos (SILVA: 1996. p. 37-38). As terras portuguesas, marcadas pelo regime feudal, em sua maior parte tinham senhorios, restando assim apropriadas, ainda que em muitos casos não cultivadas e tampouco arrendadas.

O objetivo da norma era exterminar a ociosidade das terras, impondo aos senhorios a obrigação de cultivo, sob pena de perda do domínio da terra. Já que as terras ociosas, terras não cultivadas e tampouco arrendadas, seriam compulsoriamente devolvidas (na verdade, retomadas) ao senhor de origem (a Coroa), tornando-se terras devolutas (no sentido de terras devolvidas) a serem novamente distribuídas para que fossem lavradas e cultivadas. Por meio desse instituto jurídico, Portugal evitou o esvaziamento do campo e o desabastecimento das cidades. Conntudo, no século XVI (período do descobrimento do Brasil) o sistema sesmarial já não surtia mais os efeitos desejados em Portugal, caindo assim em desuso. Ainda assim, as Ordenações Manuelinas, editadas em 1514, reestruturam o instituto, que por sua vez foi repetido integralmente nas 
Ordenações Filipinas de 1603. No sistema sesmarial português, o Sesmeiro era a autoridade real dotada de competência para ceder glebas de terras ociosas ou abandonadas (que, pertencentes a algum senhorio, em outros tempos foram lavradas e aproveitadas, e agora não mais são), limitadas a um tamanho que não fosse tão grande a ponto do próprio beneficiário não poder cultivá-las.

O instituto jurídico das sesmarias foi extinto por uma Resolução, datada de 17 de julho de 1822, proibindo, a partir de então, novas concessões e reconhecendo a legitimidade daquelas que tivessem obedecido a norma, medidas, demarcadas, lavradas e confirmadas. A extinção do instituto deu-se "por sua absoluta incompatibilidade com o novo sistema jurídico estruturado no final do século XVIII e começo do XIX” (SOUZA FILHO: 2003. P. 63-64), que impunha ao Estado o dever de garantir os direitos e liberdades individuais e de não intervir na economia e tampouco na propriedade privada (garantida expressamente no inciso XXII do art. 179 da Constituição Imperial de 1824). Isto porque a nascente propriedade privada e absoluta da terra não admitia um instituto jurídico que apenas concedesse o uso da terra e ainda condicionasse tal concessão à satisfação de algumas medidas que determinam a própria forma de usufruto.

De 17 de julho de 1822 a 18 de setembro de 1850, o Brasil permaneceu sem dispor de qualquer legislação fundiária que regulamentasse a transmissão de terras públicas desocupadas para particulares. O período é denominado “período de posses”.

Diante de uma ocupação desordenada de terras crescente e do temor de que uma eventual libertação de escravos pudesse promover uma ampla ocupação do território, a Lei n. ${ }^{\circ}$ 601, conhecida como Código Imperial de Terras, é editada em 1850.

Tal lei deixa evidente que sua principal finalidade é dispor sobre a forma de aquisição originária das terras devolutas do Império, que já não possuem mais o sentido atribuído pelo sistema sesmarial (terras devolvidas, na verdade retomadas, à Coroa para serem novamente distribuídas devido a sua ociosidade). Terras devolutas passaram a ser não as desocupadas, como ensinam alguns manuais e dicionários, mas as legalmente não adquiridas. É um conceito jurídico e não físico ou social. Não quer dizer terra desocupada, mas terra sem direito de propriedade definido; é um conceito, uma abstração, uma invenção jurídica. A mera ocupação de fato não gerava domínio jurídico, que exigia o título do Estado ou o reconhecimento, pelo Estado, de um 
título anterior, ou ainda o uso público. Ainda que a terra estivesse ocupada por trabalhadores, índios, quilombolas, pescadores, produtores de subsistência ou qualquer outro sem o beneplácito do Estado, não perdia a sua qualidade jurídica de devoluta.

Logo no seu artigo $1^{\circ}$ o diploma legal já estabelece que as terras devolutas poderão ser adquiridas única e exclusivamente por compra, ressalvando apenas a possibilidade de concessão gratuita de terras situadas em fronteira. Contudo, a Lei Imperial de Terras não ignorou o processo desordenado de ocupação territorial ocorrido nas últimas duas décadas, por isso definiu as terras devolutas por exclusão, adotando critério residual. Dessa maneira, definiu as classes de ocupação de terras no Brasil e criou mecanismos de legalização exclusivamente para grandes empreendimentos agrícolas.

A perversidade do sistema de regularização de terras criado pela Lei n. ${ }^{\circ}$ 601/1850 reside no fato de que "os simples roçados, derribadas ou queimas de mattos ou campos, levantamentos de ranchos e outros actos de semelhante natureza, não sendo acompanhados da cultura effectiva e morada habital” não são considerados suficientes para a revalidação de sesmarias e tampouco para a legitimação de qualquer posse (artigo $6^{\circ}$ ).

Dessa feita, a legitimação de posse foi vedada aos pequenos produtores agrícolas de subsistência e aos povos e comunidades tradicionais, pois somente grandes empreendimentos agrícolas poderiam demonstrar "cultura effectiva".

Em 1891, a primeira constituição federal e republicana passou aos Estados, recémcriados, o domínio das terras devolutas. As oligarquias fundiárias, proprietárias de grandes extensões de terras, foram sendo formadas nos séculos anteriores e adquirindo terras em sesmarias ou comprando terras devolutas, no regime da Lei n. ${ }^{\circ}$ 601/1850. Estes poderes se concentravam nas Províncias que vieram a se transformar em Estados Membros. Assim, no momento em que a Constituição de 1891 transferiu as terras devolutas para os Estados entregou o poder de distribuição, exatamente, para as elites fundiárias, que tinham interesse na manutenção do status quo. Quer dizer, quando a concessão de terras devolutas passou para os Estados, criados em 1891, as oligarquias locais assumiram o incontrolado direito de distribuição de terras devolutas, inclusive podendo alterar as regras contidas na Lei $n .^{\circ}$ 601/1850, porque passaram a ter competência legislativa, reproduzindo, aprofundando e ampliando o injusto sistema do 
latifúndio, com as consequências que até hoje assistimos de violência no campo e miséria na cidade.

Vale ressaltar que nas terras devolutas transferidas ao domínio dos Estados e posteriormente vendidas, concedidas em aforamento ou doadas às oligarquias estão incluídas aquelas com presença real de pequenos produtores agrícolas de subsistência e de povos e comunidades tradicionais que não dispunham de título das terras.Atores sem acesso a qualquer direito, sem a própria condição de sujeito de direitos, não podiam manifestar elementos considerados pelo direito como necessários à aquisição da propriedade. Não poderiam ser donatários de terras ou titulares de posse, tampouco adquirentes pelos ditames da Lei de Terras.

\section{A cristalização da propriedade privada}

A modernidade ${ }^{6}$ deixa seu legado, principalmente na questão do uso da terra. “Tudo o que não pudesse ser materializado em patrimônio e não pudesse ter um valor ainda que simbólico, também estava fora do direito” (SOUZA FILHO: 2005. p. 168.), pois, conforme ensina Pietro Barcelona, o conceito de propriedade privada, como forma geral de disponibilidade das coisas, se converte em norma de funcionamento de toda a sociedade e das relações humanas (BARCELONA: 1996. p. 20)7.

A ideia de apropriação nos remete ao conceito de propriedade, cuja história da garantia contempla a própria história do Direito $^{8}$ e "Pode-se, lançando um olhar sobre a modernidade ocidental, enxergar a construção do discurso proprietário: um determinado modelo de propriedade torna-se em princípio do direito moderno, por conta do centralismo ocupado pelo direito privado do oitocentos” (CORTIANO JÚNIOR: 2001. f. 3).

\footnotetext{
6 “A modernidade contém tanto 'civilização' como 'barbárie'. Contém os sistemas de pensamento da certeza absoluta, que produzem fanatismo, intolerância e não comportam a alteridade, e os sistemas de pensamento que não buscam a totalização e suportam a alteridade. A modernidade contém os dois sistemas de pensamento, da dúvida e da certeza, que vou qualificar como a civilização e a barbárie, já que são as certezas absolutas que justificam a intolerância e a violência em relação ao diferente.” (KEHL, Maria Rita. Civilização Partida. In: NOVAES, Adauto (Org.). Civilização e Barbárie. São Paulo: Companhia das Letras, 2004. p. 105)

${ }^{7}$ BARCELONA, Pietro. El individualismo propietario. Madrid: Trotta. p. 20.

8 "A história do Direito é, em boa medida, a história da garantia da propriedade”. (FACHIN, Luiz Edson. Teoria Crítica do Direito Civil. Rio de Janeiro: Renovar, 2000. p. 71)
} 
Paolo Grossi destaca que a visão individualista e potestativa da propriedade privada moderna é resultado de um processo histórico, mas que foi mascarado pela classe burguesa como verdade redescoberta, deturpando seu conceito e valor:

Destes alicerces especulativos nasce aquela visão individualista e potestativa de propriedade que comumente chamamos a 'propriedade moderna', um produto histórico que, por ter se tornado bandeira e conquista de uma classe inteligentíssima, foi inteligentemente camuflado como uma verdade redescoberta e que quando os juristas, tardiamente, com as análises revolucionárias e pós-revolucionárias na França, com as pandectísticas na Alemanha, traduzem com o auxílio do instrumental técnico romano as intuições filosófico- políticas em regras de direito e organizam-nas, de respeitável consolidação histórica se deformou em conceito e valor: não o produto de uma realidade mutável tal como foi se cristalizando, mas o cânone com o qual medir a mutabilidade da realidade. $^{9}$

Não obstante Grossi delimitar que sua análise pende muito mais para os aspectos jurídicos do instituto "propriedade privada”, ele mesmo admite que a mentalidade formadora da concepção de propriedade é resultado de uma antropologia - uma visão do homem sobre o mundo - e, por outro lado, do elo estreito com uma ideologia que é resultante de interesses vitais de indivíduos e classes, o que faz com que se supere a superficialidade das formas. ${ }^{10}$

Acrescente-se um esclarecimento que concerne à propriedade: nela, talvez mais do que em qualquer outro instituto de direito, exalta-se e se exaspera o que se está dizendo do agora jurídico, porque ela, rompendo a trama superficial das formas, liga-se necessariamente, por um lado, a uma antropologia, a uma visão do homem do mundo, por outro, em graça de seu vínculo estreitíssimo com interesses vitais de indivíduos e classes, a uma ideologia. A propriedade é, por essas insuprimíveis raízes, mais do que qualquer outro instituto, mentalidade, aliás mentalidade profunda. (GROSSI: 2006. p. 31)

Grossi afirma, com razão, que a propriedade feudal, assim como qualquer forma de propriedade constituída no curso da história, detinha um conteúdo mínimo que formava o dominium, caracterizado pelo poder exercido, de fato, pelo sujeito sobre o objeto, o que Paolo

\footnotetext{
${ }^{9}$ GROSSI, Paolo. História da propriedade e outros ensaios. Tradução de Luiz Ernani Fritoli e Ricardo Marcelo Fonseca. Revisão técnica de Ricardo Marcelo da Fonseca. Rio de Janeiro: Renovar, 2006, p. 12.

${ }^{10}$ Grossi utiliza o termo mentalidade em toda sua análise sobre a propriedade medieval referindo-se como sinônimo refinado de "costume". (GROSSI, Paolo. História da propriedade e outros ensaios. Tradução de Luiz Ernani Fritoli e Ricardo Marcelo Fonseca. Revisão técnica de Ricardo Marcelo da Fonseca. Rio de Janeiro: Renovar, 2006, p. 23)
} 
Grossi aponta ser uma relação frontal entre eles - sujeito e objeto - sem a interferência de intermediários, sendo que o domínio útil representa situação a real da mentalidade vigente no momento medieval (GROSSI: 2006. p. 23).

A imposição definitiva da propriedade moderna sobre a medieval, portanto, quando são cortados todos os laços de momentos de interseção histórica, é fruto de longo processo histórico que se inicia no século XIV e que finda apenas no século XIX, quando a mentalidade moderna de apropriação triunfa e consagra o capitalismo como uma nova ordem político-econômica (GROSSI: 2006. p. 62-63)

A propriedade torna-se um capítulo da história da transformação humanística geral, certamente não o último, aliás um dos mais relevantes, um dos pontos de compromisso da nova especulação. E não surpreende que, enquanto a mentalidade jurídica continua a desenhar e aplicar figuras tradicionais da velha ordem que persiste e ainda por muito tempo persistirá, as primeiras intuições do novo não sejam legíveis nas páginas misoneístas dos jurisconsultos, mas nas pré-figurações da nova ordem das quais estão repletas as reflexões dos teólogos e dos filósofos. A eles é confiada a erosão das velhas certezas antropológicas e a criação de novas, e serão eles a delinear aquela renovada antropologia do pertencimento que terá a função de insubstituível suporte para a futura mentalidade jurídica. (GROSSI: 2006. p. 64)

Para Grossi, a linha divisória essencial entre o pertencimento medieval e o pertencimento moderno está na simplicidade deste e na complexidade daquele, que contempla "tantos poderes imediatos sobre a coisa, diversos em qualidade segundo as dimensões da coisa que os provocou e legitimou, cada um dos quais encarna um conteúdo proprietário, um domínio (o útil e o direto)"11, e, mais, no aspecto subjetivo, assim desenvolve.

Numa análise contundente, Grossi se reporta à “de simplicitate Dei” dos escolásticos de teologia dogmática, onde se considera que graças à simplicitas Deus é pura essência separada da existência; trata-se de um processo de pelo qual passa a propriedade, que se vincula a um sujeito caracterizado pela vontade ${ }^{12}$, fazendo da propriedade a imagem e semelhança do sujeito individual. Acrescenta Grossi que “de dimensão das coisas a propriedade tornou-se dimensão do

\footnotetext{
${ }^{11}$ GROSSI, Paolo. Idem, p. 66.

${ }^{12}$ GROSSI, Paolo. História da propriedade e outros ensaios. Tradução de Luiz Ernani Fritoli e Ricardo Marcelo Fonseca. Revisão técnica de Ricardo Marcelo da Fonseca. Rio de Janeiro: Renovar, 2006, p. 68-69.
} 
agente; ao invés de identificar-se grosseiramente no bem-objeto, procura no interior do sujeito a sua identificação primeira”13.

A propriedade passa a se situar na renovada ideia de dominium sui, que se torna a pedra angular do pensamento moderno. "O seu significado é preciso: um indivíduo que se descobre essencialmente proprietário no fundo de seus mecanismos mais autenticamente naturais, que interpreta como divisões proprietárias do si gestos e comportamentos instintivos de índole primordial” ${ }^{14}$. O dominium sui independe de entidades externas, pois é uma realidade ontológica completa situada no interior do homem, fazendo do sujeito um personagem fortalecido no interior de uma carga agressiva que o projeta dominadoramente sobre o mundo. Enquanto a propriedade eleva-se de plano para dimensão do sujeito, “maturava-se o destaque definitivo de todos os outros direitos reais: estruturas organizadoras da realidade econômica e repletas de conteúdos econômicos” 15

Além da simplicidade, a propriedade moderna agrega como alicerce a abstração, com o domínio do caráter subjetivo na relação entre sujeito e coisa, sendo o conteúdo do bem um mero acidente que não repercute na relação principal da apropriação.

A propriedade já é, nesta versão tão exasperadamente subjetivista, uma capacidade, capacidade de envolver e dominar todo conteúdo, rejeitando portanto todo conteúdo como contribuição à sua qüididade. O conteúdo já é somente um acidente, que nunca está em condições de repercutir sobre a substância da relação. Ao lado - a atrás - da simplicidade, eis o segundo traço tipificador da propriedade nova: a abstração. ${ }^{16}$

Mas a par disto, Grossi demonstra que a propriedade nova encerra em si vestígios da propriedade medieval. Ao analisar o Code civil napoleônico, destaca tratar-se de "quase um palimpsesto antigo" que "pode revelar uma dupla escritura, e oferecer-nos um testemunho historicamente interessante” onde um mesmo artigo (no caso, o artigo 544) contém uma dupla escritura: “a ideia destoante de uma propriedade como soma de poderes, como resultado da

\footnotetext{
${ }^{13}$ GROSSI, Paolo. Idem, p. 69.

${ }^{14}$ GROSSI, Paolo. Idem, p. 69-70.

${ }^{15}$ GROSSI, Paolo. Idem, p. 70.

${ }^{16}$ GROSSI, Paolo. Idem, p. 71.
} 
adição de um gozar e de um dispor, que deveria ter tornado aceitável o já inaceitável e não-aceito princípio da divisão da propriedade»"17.

A velha mentalidade “continua a fazer emergir uma noção composta de propriedade”, distinta qualitativamente de direito real, que é tomado como "fração separada do feixe total que somente na sua soma é a propriedade” ${ }^{18}$. Portanto, mesmo na construção do modelo moderno, a propriedade é complexa. Todavia, a propriedade passa a ser absoluta para um sujeito absoluto com a Pantectística alemã.

Aqui a propriedade se torna criatura jurídica congenial ao homo oeconomicus de uma sociedade capitalista evoluída: um instrumento ágil, conciso, funcionalíssimo, caracterizado por simplicidade e abstração. Simples como é o sujeito, realidade unilinear sobre a qual se modela e da qual é como que a sombra no âmbito dos bens; abstrata como o indivíduo liberado da nova cultura, do qual quer ser uma manifestação e um meio validíssimo de defesa e de ofensa. É nesta transcrição do sujeito que ela reclama a sua unidade e a sua indivisibilidade: una e indivisível como ele, porque como ele é síntese de virtude, capacidade e poderes. Uma transcrição aderente a ponto de parecer quase uma fusão: a propriedade é somente o sujeito em ação, o sujeito à conquista do mundo. Idealmente, as barreiras entre mim e meu caem. ${ }^{19}$

E esta propriedade atrelada ao sujeito, está atrelada ao sujeito transcendental. E nesta concepção proprietária que se sobressai com a modernidade, na construção do direito pátrio, duas teorias são colocadas em destaque: Friedrich Karl von Savigny e Rudolf von Ihering. Divisou o Savigny dois elementos constitutivos da posse: o corpus e o animus domini. A subida importância conferida a este segundo elemento veio a consagrar a doutrina como teoria objetiva, assim considerada a exteriorização dos poderes dados ao proprietário. A vontade de possuir para si que origina a posse jurídica, e quem possui por outro é detentor, razão porque o representante não possui porque non habel animum possidentis; o locatário também não possui porque conducenti nom sit animus possessionis adipiscendi”. $\quad$ Além do elemento ético - a intenção - é indispensável para a aquisição da posse, o fato material da detenção - corpus, isto é, a possibilidade física de dispor da coisa com exclusão de qualquer outra pessoa, de exercer sobre ela os poderes inerentes ao domínio.

${ }^{17}$ GROSSI, Paolo. História da propriedade e outros ensaios. Tradução de Luiz Ernani Fritoli e Ricardo Marcelo Fonseca. Revisão técnica de Ricardo Marcelo da Fonseca. Rio de Janeiro: Renovar, 2006, p. 79.

${ }^{18}$ GROSSI, Paolo. Idem, p. 81.

${ }^{19}$ GROSSI, Paolo. Iddem, p. 81-82. 
A mais popular das teorias possessórias foi a de Savigny, sobre cujos destroços Ihering erigiu o Fundamento dos Interditos Possessórios. Ihering ${ }^{20}$, embora reconhecendo o corpus et animus, relacionou-os a um vínculo jurídico, a que todos os fatos sociais estão subordinados. Correu logo a doutrina sob a expressão de teoria objetiva, para a qual a vontade individual é de todo impotente e indiferente. É uma regra de direito objetivo, uma disposição de lei que decide se temos diante de nós a posse ou a detenção, não importando a vontade individual na medida em que a posse deriva imediatamente da regra jurídica, do direito objetivo; exclui o elemento subjetivo que era o característico máximo da doutrina de Savigny - a vontade de possuir para si, animus rem sibi habendi; assim lhe é absolutamente indiferente a qualificação particular da vontade de possuir; o autor não tem necessidade de sustentar a existência do animus domini e seu adversário não pode sustentar a não existência do animus domini .

O Código Civil de 1916, com vigência a partir de 1917, não conceituou a posse. O legislador opinou pela caracterização do possuidor: "Art. 485 - considere-se possuidor todo aquele que tem de fato o exercício pleno, ou não, de algum dos poderes inerentes ao domínio ou propriedade”. Acolhida foi a doutrina de Ihering e nenhum dos nossos tratadistas investe contra a assertiva. Comenta Clóvis Beviláqua: “O Código Civil brasileiro adotou o pensamento de Ihering quando ao conceito de posse como visibilidade da propriedade, ainda que a sua proteção possa favorecer a quem não é proprietário, nem exerce algum direito real”21.

O Código Civil brasileiro adotou a teoria da Ihering, devendo a posse subordinar-se, necessariamente, ao aspecto jurídico da relação, mantendo-se no terreno sólido do conceito que adotou: posse é a exteriorização da propriedade e dos poderes a ela inerentes. ” (op. cit., PP. 67$68)$.

O relator do projeto do Código Civil, Luis Domingues, assinalou em seu reconhecido parecer: "Não sofre dúvida que a obra de Savigny, admirável a tantos títulos, não mais se recomenda pela definição de posse. A posse existe com a intenção de dono, mas também pode

${ }^{20}$ Rodolfo Von ihering, um dos mais eminentes jurisconsultos do século XIX. Nasceu em Aurichem (1818), Alemanha, e morreu em Gotinga (1892). Escreveu Espírito do Direito Romano (1852), Questões de Direito Civil sem Decisões (1847), A Luta pelo Direito (1872), A Intenção do Direito (1883), A Jurisprudência na Vida Quotidiana (1893) etc.

${ }^{21}$ BEVILÁQUA, Clóvis. Direto das coisas. Rio de Janeiro: Freitas Bastos, 1941. v. I, p. 30. 
existir sem ela e até com reconhecimento de outro dono, e bem assim com o poder físico de dispor da coisa como sem ele; e se em geral sua defesa é exercida contra as agressões de terceiro, não raro o é contra as do dono, reconhecido como tal pelo próprio possuidor”22.

O ingresso da teoria objetiva na lei civil nacional é festejado. Astolfo Rezende assim se manifesta:

O triunfo de Clóvis foi completo, porque a consciência do Brasil já estava amadurecida para repelir idéias anacrônicas, ligadas à velha metafísica jurídica. Não faltou, porém, a resistência ou reação da velha guarda, daqueles que haviam educado o seu espírito segundo os tradicionais métodos espiritualistas. ${ }^{23}$

Segundo Clóvis Beviláqua, “Outras teorias têm apparecido; mas ou são modificações das apontadas; ou são de valor somenos” 24 . Pode-se afirmar que, a partir da segunda metade do século XIX, pelo menos em solo brasileiro, praticamente não há autor que não parta ora do sistema de pensamento de Savigny, ora do de Ihering (dependendo da época analisada), para explicar e sustentar boa parte do regime jurídico da posse. Para se compreender no Brasil a conformação jurídica da matéria possessória sem conhecer, ainda que em linhas gerais, as duas teorias e suas consequências no direito positivo nacional.

Isto porque toda a formação histórica da ideia de posse no discurso letrado (doutrinário) do direito brasileiro, a partir da segunda metade do século XIX, acaba tendo como ponto de partida e núcleo fundamental (ainda que não exclusivo) exatamente uma das teorias mencionadas ou elementos das teorias consagradas por esses autores, dependendo principalmente do período analisado. ${ }^{25}$

Para Antonio Hernández Gil, qualquer tipo de uso não implica em posse, é essencialmente, um uso qualificado. A projeção mais direta da pessoa sobre as coisas, determinante de consequências jurídicas dirigidas à manutenção de uma situação dada. ${ }^{26}$ Indagando por que se protege a posse, constata o autor que a mesma formulação não é feita em relação à propriedade. Por que, pois, se agita a respeito da posse? Poderia dizer que o século passado quase inverte os

22 apud FUlGÊNCIO, Tito. Da Posse e das Acções Possesorias. São Paulo: Saraiva \& Cia Editores, 1936, pp. 6-7. (Aqui propositadamente adotada uma obra da própria época em que pululavam as discussões e reafirmações sobre as teorias objetiva e subjetiva, destacando-se para a triste constatação de que sequer se cogitava o enorme contingente de realidade que não se enquadraria nos cânones da teoria objetiva).

${ }^{23}$ REZENDE, Astolfo. A posse e sua Proteção. 2 vols. Livraria Acadêmica, 1937, p. 171-175.

${ }^{24}$ BEVILÁQUA, Clóvis. Ob. cit.. p. 19

${ }^{25}$ STAUT JÚNIOR, Sérgio Said. Posse e dimensão jurídica no Brasil: recepção e reelaboração de um conceito a partir da segunda metade do século XIX ao Código de 1916. Curitiba: Juruá, 2015, pp. 156-157.

${ }^{26}$ GIL, Antonio Hernández. La funcion social de la posesion. Madrid: Alianza Editorial S.A., 1969, pp. 6-7. 
termos das perguntas. Então o fundamento da posse era tema inquietante e polêmico enfrentando com preferência pelos juristas. As disputas em torno da propriedade, e sempre a de se entender propriedade privada, já haviam começado. ${ }^{27}$

Enquanto Savigny atua no plano psicológico e íntimo da atitude anímica, Ihering estabelece a subordinação na realidade objetiva das instituições. Um se conforma com a vontade tendente para a propriedade e persevera a ideia; o outro, vendo na propriedade o sustento único da posse, afirma a propriedade e independência dela. ${ }^{28}$ Ihering, que dedicou um acúmulo de energias dialéticas e colocar a propriedade onde Savigny havia situado a pessoa, isto é, no centro da proteção possessória, realizou um maior esforço se possível para eliminar a localização que Savigny havia outorgado a propriedade: o animus domini. Isto porque o corpus e o animus não são, para Ihering, elementos separáveis. ${ }^{29}$

Ihering substitui o dado psicológico pelo pressuposto sociológico. Efetua a eliminação daquele a custas de aprofundar a raiz da posse nas estruturas dominicais. Ao invés de afastamento há aproximação. Com liquidação do fator psicológico, toda exploração consciente e querida da coisa dá lugar à posse, ainda quando se trate de uma exploração que exclua toda externalização do direito de propriedade. O conceito econômico da posse veio a substituir o conceito jurídico. A posse é a apropriação econômica das coisas sem relação alguma com a possível existência de um direito sobre a coisa.

Para Savigny, há duas espécies de direitos sobre o solo: a propriedade sobre o ager privatus, com a reivindicação, e a posse sobre o ager publicus, com os interditos. Somente o ius possessionis forma parte da teoria possessória propriamente dita. Ihering, que dedicou um acúmulo de energias dialéticas e colocar a propriedade onde Savigny havia situado a pessoa, isto é, no centro da proteção possessória, realizou um maior esforço se possível para eliminar a localização que Savigny havia outorgado a propriedade: o animus domini. O corpus e o animus não são, para Ihering, elementos separáveis. Substitui o dado psicológico pelo pressuposto sociológico. Efetua a eliminação daquele a custas de aprofundar a raiz da posse nas estruturas dominicais. Ao invés de afastamento há aproximação. Por isso ocorre que quem hoje se plante o

\footnotetext{
${ }^{27}$ GIL, Antonio Hernández. Ob. Cit., pp. 9-10.

${ }^{28}$ GIL, Antonio Hernández. Idem, p. 27.

${ }^{29}$ GIL, Antonio Hernández. Ob. Cit., p. 31.
} 
problema de inquirir a função social da posse, como instituição corretora da propriedade, encontra um ponto de partida mais útil na formalista Savigny do que na realista Ihering. Aquele, colocando a posse a serviço da pessoa e em missão de paz. Por isso, em um sentido estrito, a posse é identificada com o exercício do direito pelo titular.

A posse que é qualificada pelo direito como fato jurígeno é uma posse atrelada ao conceito moderno de propriedade, e, mais, dentro de um a classificação que afasta o fator psicológico, anímico, voltando-se para o conceito de propriedade. A posse é a exteriorização dos poderes do proprietário, e nesta condição é que passa a ter o condão de modo de aquisição da propriedade. Há certa tautologia, intencional, para que uma concepção ampla de posse não prevaleça e para que o fator anímico tenha contornos formais. De tal modo, que aqueles que usam de forma não ostensiva não possa ser considerado possuidor.

A posse não é protegida por facilitar a defesa da propriedade, mas aquela e esta são, bem que de modo diverso, protegidas pela mesma razão: que é fazer possível aos indivíduos a constituição do patrimônio destinado à satisfação de suas necessidades. O social não conta aqui em um sentido propriamente comunitário. A posse é, sobretudo, um meio de atribuição da riqueza e do gozo da mesma. ${ }^{30}$

A condição de possuidor é determinante para alçar-se ao exercício de fato sobre a coisa o condão de aquisição da propriedade. Dentre os modos de aquisição da propriedade, somente um é decorrente da posse, a usucapião, que demanda requisitos específicos (tempo, qualidade, título...) a restringir ainda mais a possibilidade de determinado exercício de fato gerar o direito de propriedade.

O exercício de poderes fato sobre as áreas de terras pelas comunidades quilombolas não resultou, na maioria dos casos, em aquisição da propriedade, porque diante da qualificação legal e, muitas vezes, da interpretação judicial, não se trata de exteriorização dos poderes de proprietário, da posse objetiva, em que animus e corpus se fundem em um conceito perverso que restringe as possibilidades de acesso ao reconhecimento pelo Estado. Os ocupantes quilombolas lá estavam, sem acesso à documentação que os possibilitasse de opor seu direito contra todos. A ocupação se deu através de uma territorialidade específica, integrada pela identidade com a terra,

\footnotetext{
${ }^{30}$ GIL, Antonio Hernández. Ob. Cit., p. 59 (tradução libre).
} 
num verdadeiro elemento anímico que insistiu o direito proprietário em deixar de reconhecer, mostrando a que veio.

Essas outras formas de ocupação, de exercícios de fato diferentes daquelas acolhidos pelo direito, são territorialidades que lutam com o sistema proprietário e podem ser consideradas territorialidades rivais, desconsideradas pelo Estado, tema que será abordado no item seguinte.

\section{A desconsideração das territorialidades rivais}

As ocupações de uso comum guardam características pré-modernas não reconhecidas pelo direito que estão nos caracteres mal apagados do palimpsesto mencionado por Grossi ${ }^{31}$. O artigo 544 do Código Civil Francês é, sem dúvida, é o primeiro dispositivo legal a dar estrutura jurídica ao capitalismo, é reveladora da mudança sofrida: “a propriedade é o direito de fazer e de dispor das coisas do modo mais absoluto, contanto que delas não se faça uso proibido pelas leis ou pelos regulamentos”. Segundo Marés ${ }^{32}$, fazer e dispor são verbos que enlaçam esse direito de propriedade, e, adverte, “quem tem o direito absoluto de fazer, tem também o de não fazer”.

Com o advento da modernidade, o uso deixou de ser o fundamento da propriedade. Ao contrário, o uso decorre agora da propriedade, o proprietário tem o direito inerente de usar a propriedade ou de a dispor a uso alheio. Nessa concepção, o fundamento da propriedade é o direito de dispor, isto é, o ato pelo qual, um proprietário legítimo transfere o bem a outrem. É a legitimidade do contrato. O contrato legítimo gera uma propriedade legítima. O problema é a propriedade originária, a que não precisou de contrato, a primeira, inicial. Para as coisas feitas, produzidas pelo ser humano é o trabalho. O trabalho origina a propriedade. No caso da terra também é o trabalho. Então voltaríamos ao uso, proprietário da terra é quem nela trabalha. Errado, para o direito capitalista! O uso da terra só gera propriedade em duas situações: 1) quando o Poder Público, o Estado, ou o Rei formalmente autorizam ou concedem o direito de uso, como no caso das sesmarias (neste sistema o uso tinha que ser mantido) ou como no

\footnotetext{
31 Para Grossi, a propriedade moderna está assentada em um “palimpsesto”. O Código Civil de 1916, com vigência à partir de 1917, adotou o mesmo "palimpsesto".

32 MARÉS, Carlos Frederico. Função Social da Propriedade. In Reforma Agrária e Meio Ambiente: teoria e prática no estado do Paraná. Claudia Sonda (Org.), Silvia Cristina Trauczynski (Org.). Curitiba: ITCG, 2010, p. 183.
} 
cercamento inglês; 2) a usucapião, que nada mais é do que o uso continuado, como se dono fosse, de um bem, em geral é exigido pela lei que o usuário, de boa-fé, se considere proprietário.

Mas no Brasil e muitos outros lugares onde havia terra a serem adquiridas por ação de conquista, diferente de Portugal, Inglaterra e França onde o domínio já estava consolidado, a lei limitou o acesso, permitindo somente a quem fosse amigo do Rei, ou tivesse suficiente capital para contratar trabalhadores ou, melhor ainda, as duas coisas ao mesmo tempo. No Brasil, o instituto usado para isso foi o das sesmarias, criado em 1375 e que obrigava o cessionário a usar a terra sob pena de perdê-la de volta ao Rei, que poderia cedê-la a outra pessoa. Entretanto, se produzisse na terra confirmaria a concessão e na prática se tornaria proprietário, podendo vendêla, doá-la ou transferi-la por contrato. Esta construção prática da propriedade da terra se tornou lei em 1850, com a Lei de Terras do Império, Lei n. ${ }^{\circ}$ 601, de 18 de agosto de 1850, que criou o instituto da concessão de terras devolutas, gerando um direito originário próprio. Essa lei veio reconhecer como propriedade todas as sesmarias confirmadas pela produção.

Resolvido o problema da propriedade originária, o uso volta a ser apenas um direito do proprietário, e, como direito, seu exercício depende da vontade do titular. Quer dizer, todo aquele que adquirisse o título de propriedade, seja pelo contrato (ou sucessão), seja pelo reconhecimento originário, já tinha o direito de não usá-la. A terra, assim, passou a ser um bem como outro qualquer, uma mercadoria sem qualquer restrição ética, a liberdade do sujeito do direito autorizava a acumulação de quanta terra quisesse ou pudesse ter, da mesma forma que o ouro, a prata e o dinheiro. Como qualquer mercadoria não consumível sujeita à especulação do capital.

Comunidades campesinas não tiveram a possibilidade de garantir o reconhecimento das ocupações pelo direito positivado, pois, assim como o modelo de propriedade privada recepcionado, a posse valorada na forma de usucapião como modo de aquisição da propriedade também seguia requisitos formais e objetivos. Inalcançáveis pelos quilombolas ou para quaisquer outros atores integrantes das territorialidades rivais.

As territorialidades ${ }^{33}$ rivais aqui defendidas se tratam de formas de ocupação que mantêm um caráter coletivo, o uso comum, e destoam daquilo que a modernidade buscou adotar como única possibilidade: o uso privado da terra.

33 Sobre a importância do território para comunidades tradicionais, a Corte Interamericana de Direito Humanos proferiu decisões paradigmáticas. Por exemplo, no caso da Comunidade Indígena Yakye v. Paraguai, decidido em 17 
Recorrendo a um bom exemplo de territorialidade rival ao modelo proprietário, pode-se analisar as comunidades quilombolas, que se implantam com todas as dificuldades de uma terra estranha, em condições ambientais adversas e na necessidade de resistência ${ }^{34}$. As terras eram ocupadas coletivamente a fim de refúgio do jugo escravocrata e garantia da sobrevivência; eram, portanto, em regra, distantes dos quinhões mais disputados ainda na distribuição sesmarial ou de posses $^{35}$. Mas as fronteiras avançaram e propiciaram uma trajetória de conflitos inflamados por um discurso proprietário excludente das diferentes maneiras de apropriação da terra, dando validade aos cânones positivistas aplicáveis ao tema. Tais circunstâncias reduziram paulatinamente a extensão de terras ocupadas ${ }^{36}$ e implicou no despojamento de muitas comunidades das suas áreas tradicionais (resumidas a pequenos aglomerados de casas e quintais), situação agravada com a Lei de Terras e, após, com a codificação do Direito Civil.

Para compreender a dimensão dessas diferentes formas de uso da terra e seu reconhecimento, há que ampliar a dimensão do jurídico e valorar a produção do direito em seus contextos culturais.

de junho de 2005, a Corte observou que "a garantia do direito de propriedade comunitária dos povos indígenas deve levar em conta que a terra está estreitamente relacionada com as suas tradições e expressões orais, seus costumes e línguas, suas artes e rituais, seus conhecimentos e usos relacionados com a natureza, suas artes culinárias, seu direito consuetudinário, sua vestimenta, filosofia e valores. Em função do seu entorno, sua

integração com a natureza e sua história, os membros das comunidades indígenas transmitem de geração em geração este patrimônio cultural imaterial”.

34 Segundo Chiavenato (CHIAVENATO, Júlio José. O Negro no Brasil: da senzala à abolição. São Paulo: Moderna, 1999, p.65) o primeiro quilombo brasileiro surgiu em 1575, sendo que centenas se espalharam pelos diferentes recantos do país; Mello confirma que documentos datados de 1602 também tratavam deste assunto (MELLO, Mário. A república dos Palmares. In I Congresso Afro-Brasileiro. Recife 1934. Novos Estudos Afrobrasileiros, Recife: Fundação Joaquim Nabuco. Editora Massangana: 1988, p.181). Schwartz apresenta um relato escrito por um jesuíta anônimo que, ainda em 1619, descreve os quilombos baianos (SCHWARTZ, Stuart. Escravos, roceiros e rebeldes. Bauru (SP): EDUSC, 2001, p. 222), informação confirmada por Fiabani, que ainda acrescenta a notícia da destruição da experiência pelo Governador Geral da Bahia, Luiz de Brito de Almeida (FIABANI, Adelmir. Mato, palhoça e pilão: o quilombo da escravidão às comunidades remanescentes [1532-2004]. São Paulo: Expressão Popular, 2005, p.47).

${ }^{35}$ Regime vigente entre 1824 e 1850, após a extinção do sistema de concessão de terras por sesmarias e antes da instituição do sistema de concessão onerosa (vide nota 20).

${ }^{36} \mathrm{O}$ termo ocupação é colocado propositalmente porque não se tratava de posse no sentido objetivo adotado pelo Código Civil de 1916. 
A Constituição Brasileira de 1988 dedicou todo um capítulo aos povos indígenas ${ }^{37}$, estabelecendo contornos muito superiores à trajetória constitucional brasileira ${ }^{38}$, e, embora não use a palavra diversidade, pluralismo ou multiculturalismo ${ }^{39}$, reconhece os direitos dos povos indígenas e os protege ${ }^{40}$. O texto constitucional consagra o direito dos indígenas de serem diferentes, enquanto pessoas e grupos, com seus próprios valores.

Os valores culturais das pessoas e sociedades indígenas são inerentes e constituídos permanentemente, pois a dinâmica é característica inarredável da cultura. Esses valores, informantes cotidianos das práticas sociais, constituem, portanto, seus usos, costumes e tradições, e confirmam a organização social, ou, traduzindo na esfera jurídica, uma espécie de sujeito coletivo de direito, diferente das pessoas jurídicas formais... ${ }^{41}$

A Constituição de 1988 permite que os povos indígenas permaneçam vinculados às suas respectivas organizações sociais ${ }^{42}$, deixando de lado a velha matriz integracionista, que, pressupunha a transitoriedade dos índios e sua progressiva “fusão” à sociedade envolvente, aos poucos deixando de existir enquanto pessoas e culturas diferenciadas.

\footnotetext{
${ }^{37}$ No Brasil existe uma população indígena que varia de 350 a 500 mil pessoas, em cerca de 200 etnias e 170 línguas, que se organizam em pelo menos 216 sociedades diferentes, portadoras de diferentes cosmologias que regem a maneira de ser, de se comportar no mundo, de se organizar em comunidade e lutar por seus direitos.

${ }^{38}$ As constituições de 1934, 1946, 1967 e 1969 sustentam a vertente integracionista e desconhecem a pluralidade cultural; as constituições de 1824 e 1891 não fazem referência aos povos indígenas; a Constituição de 1937 se restringe a tratar da questão fundiária.

39 "A expressão multiculturalismo designa, originalmente, a coexistência de formas culturais ou de grupos caracterizados por culturas diferentes no seio de sociedades 'modernas'. Rapidamente, contudo, o termo se tornou um modo de descrever as diferenças culturais em um contexto transnacional e global. Existem diferentes noções de multiculturalismo, nem todas de sentido emancipatório." (SANTOS, Boaventura de Sousa. Reconhecer para libertar: os caminhos do cosmopolismo multicultural. Vol. 3: Reinventar a Emancipação Social: para novos manifestos. Rio de Janeiro: Civilização Brasileira, 2003. p. 26)

40 Este mesmo reconhecimento aparece nos acordos internacionais, como o Convênio 169, da Organização Internacional do Trabalho (OIT), adotada em 26 de junho de 1989 (aprovada no Brasil pelo Decreto Legislativo ${ }^{\circ}$ 143/2002.). Tanto a ONU como a Organização dos Estados Americanos (OEA) têm discutidos declarações com este mesmo sentido. Esta concordância não significa que os países latino-americanos têm aceitado as normas internacionais, o que demonstra a insinceridade das elites locais que sempre imaginam que suas Constituições podem deixar de ser aplicadas por falta de leis que as regulamentem, e por isso permitem a inclusão de avanços na Constituições para depois restringir sua regulamentação. Na realidade, a aceitação das normas internacionais, especialmente a Convenção 169, significaria a regulamentação de suas avançadas constituições, que podem ser apenas declarações de princípios inaplicáveis frente a interesses da economia global, como veremos a seguir.

${ }^{41}$ DANTAS, Fernando Antonio de Carvalho. Humanismo latino: o Estado brasileiro e a questão indígena. In: MEZZAROBA, Orides (org.). Humanismo Latino e Estado no Brasil. Florianópolis: Fundação Boiteux; [Treviso]: Fondazione Cassamarca, 2003, p. 493.

42 Organização social entendida como "complexo de representações simbólicas relacionadas à atividade social de um povo". (Ibidem, p. 496)
}

Revista de Sociologia, Antropologia e Cultura Jurídica | e-ISSN: 2526-0251 | Maranhão | v. 3 | n. 2 | p. 18 - 44 | Jul/Dez. 2017. 
A mesma constituição que tanto avançou na questão indígena tratou apenas em suas disposições transitórias, em um único artigo, sobre a questão quilombola; também fez menção no $\S 5^{\circ}$, do artigo 216, quando estabelece o tombamento de "todos os documentos e os sítios detentores de reminiscências históricas dos antigos quilombos”. Todavia, em relação a outras experiências de uso comum da terra, diferentes da apropriação privada individual, silenciou-se o constituinte.

Os movimentos democráticos que se demarcam com o reconhecimento do multiculturalismo consolidam uma pluralidade de espaços e uma diversidade de fontes. Implicam numa retomada da demodiversidade ${ }^{43}$, com a coexistência de diferentes modelos e práticas democráticas e não a aceitação passiva do modelo liberal como caminho universal de organização política e de reconhecimento ao direito à terra.

\section{CONCLUSÕES}

É inegável “a coexistência de formas culturais ou de grupos caracterizadores por culturas diferentes no seio das sociedades modernas" 44 . O projeto da modernidade buscou reduzir a complexidade dos processos sociais submetendo-os a uma racionalidade voltada para a satisfação de necessidades individuais de cunho eminentemente econômico. Mas a vida é um complexo de elementos dados e construídos e a redescoberta de novos (ou antigos) códigos e símbolos possibilita uma identidade intercultural.

Os discursos filosóficos e jurídicos que valorizam a vida concreta, a identidade cultural e o pluralismo jurídico esbarram na fundamentação da propriedade privada que orienta o tratamento da titulação das terras de uso comum ou coletivo no Brasil. O direito de propriedade vigente permeia tanto a estrutura dos códigos civis quanto das constituições brasileiras, ao remeter-se a tradição iluminista que construiu os discursos sobre propriedade, posse, ocupação e detenção de bens públicos, que sustentam as estruturas desses instrumentos normativos.

\footnotetext{
43 SANTOS, Boaventura de Sousa. Democratizar a Democracia: os Caminhos da Democracia Participativa. Vol. 1: Reinventar a Emancipação Social: para novos manifestos. Rio de Janeiro: Civilização Brasileira, 2003. p. 71-72.

${ }^{44}$ SANTOS, Reconhecer para libertar..., p. 26.
} 
Na concepção moderna, a qualidade abstrata de proprietário de um bem representada em um título, que está atrelada a um sujeito absoluto e transcendental, que se sobrepõe ao atuar humano como integrante de um território com todas as suas manifestações existenciais e culturais.

Para o ordenamento jurídico brasileiro somente a titularidade jurídica formal e abstrata é relevante para garantir a permanência de um determinado indivíduo ou comunidade sobre a terra. A posse é tratada como um elemento fático e vinculado à propriedade. Explica-se, a posse pode se manifestar para dar concretização e exteriorização ao direito abstrato de propriedade. Mas pode, excepcionalmente, manifestar-se desvinculada da propriedade.

A ocupação sequer é tratada pelo direito e em relação aos bens públicos, só é possível se garantir a detenção, que tem menos garantias do que a posse. Uma radicalização da autonomia da posse recorre à ideia, tantas vezes repetidas, de que a posse é de fato o que a propriedade é de direito. Enquanto a propriedade se abstrai do uso, não acontece o mesmo com a posse. Nessas concepções, as territorialidades rivais, notadamente aquelas calcadas no uso comum, são negadas e ocultadas, consideradas à margem das formas reconhecidas de apropriação. Entretanto, são as territorialidades tidas à margem do sistema jurídico estatal que produzem o direito concreto aplicado à vida concreta consolidada nos saberes e práticas locais.

\section{REFERÊNCIAS}


ALMEIDA, Gabriel Gino; MARÉS, Theo. As reais consequências da proeza jurídica de separar a terra da natureza e dos povos que a ocupam. In SONDA, Claudia; TRAUCZYNSKI, Silvia Cristina. (Orgs.) Reforma Agrária e meio ambiente: teoria e prática no Estado do Paraná. Curitiba: ITCG, 2010.

ANDRADE, Julieta de. Identidade Cultural no Brasil. Vargem Grande Paulista: A9 Editora e Empreendimentos, 1999.

BARCELLONA, Pietro. El individualismo propietario. Madrid: Trotta, 1996.

BEVILÁQUA, Clóvis. Direto das coisas. Rio de Janeiro: Freitas Bastos, 1941. v. I.

BOAS, Franz. Anthropology and Modern Life. Westport, Connecticut: Greenwood Press, 1928, reimp. 1984.

BOAS, Franz. Antropologia Cultural. Trad. Celso Castro. 6. ed. Rio de Janeiro: Jorge Zahar Ed., 2010.

CHIAVENATO, Júlio José. O Negro no Brasil: da senzala à abolição. São Paulo: Moderna, 1999.

CHAUI, Marilena. Introdução. In: LAFARGUE, Paul. O Direito à Preguiça. Trad. J. Teixeira Coelho Neto. 2. ed. São Paulo: Editora Hucitec; Unesp, 1999.

CLASTRES, Pierre. A Sociedade Contra o Estado: pesquisas de antropologia política. Trad.: Theo Santiago. São Paulo: Cosac \& Naify, 2003.

CLAVERO, Bartolomé. Happy Constitution: cultura e lengua constitucionales. Madrid: Editorial Trotta, 1997.

CORTIANO JÚNIOR, Eroulths. O Discurso Proprietário e suas Rupturas: Prospectiva e Perspectivas do Ensino do Direito de Propriedade. Curitiba, 2001. Tese (Doutorado em Direito) Setor de Ciências Jurídicas, Universidade Federal do Paraná.

DANTAS, Fernando Antônio de Carvalho. O Direito Diferenciado: pessoas, sociedades e direitos indígenas no Brasil. Curitiba, 2003. Tese (Doutorado em Direito) - Setor de Ciências Jurídicas, Universidade Federal do Paraná. f.

DANTAS, Fernando Antonio de Carvalho. Humanismo latino: o Estado brasileiro e a questão indígena. In: MEZZAROBA, Orides (org.). Humanismo Latino e Estado no Brasil. Florianópolis: Fundação Boiteux; [Treviso]: Fondazione Cassamarca, 2003.

DULCE, María José Farínas. La tensión del “pluralismo” desde la perspectiva filosófica intercultural. In Derechos y Libertades - Revista del Instituto Bartolomé de Las Casas. Año VIII. Enero/Diciembre. Número 12. Universidad Carlos III de Madrid. Boletín Oficial del Estado. 2003.

DUSSEL, Enrique. Ética da libertação: na idade da globalização e da exclusão. Petrópolis: Editora Vozes, 2002. 
ENGELS, Friedrich. A Origem da Família, da Propriedade Privada e do Estado. Tradução de Ruth M. Klaus. São Paulo: Centauro, 2002.

FACHIN, Luiz Edson. Teoria Crítica do Direito Civil. Rio de Janeiro: Renovar, 2000.

FIABANI, Adelmir. Mato, palhoça e pilão: o quilombo da escravidão às comunidades remanescentes [1532-2004]. São Paulo: Expressão Popular, 2005.

FOWLER, Marcos Bittencourt; CRUZ, André Viana da; RIBEIRO, Dandara dos Santos Damas. Desapropriação para fins de reforma agrária por descumprimento da função ambiental da propriedade. In. SONDA, Claudia; TRAUCZYNSKI, Silvia Cristina. (Orgs.) Reforma Agrária e meio ambiente: teoria e prática no Estado do Paraná. Curitiba: ITCG, 2010.

FUlGÊnCIO, Tito. Da Posse e das Acções Possesorias. São Paulo: Saraiva \& Cia Editores, 1936.

GEDIEL, José Antônio Peres. Os Transplantes de Órgãos e a Invenção Moderna do Corpo. Curitiba: Moinho do Verbo, 2000

GEDIEL, José Antônio Peres; CORRÊA, Adriana Espíndola; SANTOS, Anderson Marcos dos; e SILVA, Eduardo Faria. Direitos em conflito: movimentos sociais, resistência e casos judicializados : estudos de casos - v.1. Organização de José Antônio Peres Gediel ... [et al.]. — Curitiba: Kairós Edições, 2015.

GEDIEL, José Antônio Peres. Ação Ordinário n. ${ }^{\circ}$ 2008.70.00.000158-3 JF/PR Invernada Paiol de Telha e Ação Direita de Inconstitucionalidade n. ${ }^{\circ} 3.239$ - STF. In: GEDIEL, José Antônio Peres; CORRÊA, Adriana Espíndola; SANTOS, Anderson Marcos dos; e SILVA, Eduardo Faria. Direitos em conflito: movimentos sociais, resistência e casos judicializados: estudos de casos - v.1. Organização de José Antônio Peres Gediel ... [et al.]. — Curitiba: Kairós Edições, 2015, pp. 49-65.

GEERTZ, Clifford. O Saber Local: novos ensaios em antropologia interpretativa. Tradução: Vera Mello Joscelyne. Petrópolis: Vozes, 1997.

GIL, Antonio Hernández. La funcion social de la posesion. Madrid: Alianza Editorial S.A., 1969.

GOMES, Flávio dos Santos. Quilombo do Rio de Janeiro no século XIX. In: REIS, João José; GOMES, Flávio dos Santos (Org.). Liberdade por Um Fio: história dos Quilombos no Brasil. São Paulo: Companhia das Letras, 1996.

GOMES, Orlando. Direitos Reais. 9. ed. Rio de Janeiro: Forense, 1985.

GOMES, Orlando. Raízes históricas e sociológicas do Código Civil brasileiro. 2a . ed. São Paulo: Martins Fontes, 2006.

GOMES, Orlando. Significado da evolução contemporânea do direito de propriedade. Revista dos Tribunais, São Paulo, ano 87, v. 757, p. 717-727, 1988.

GROSSI, Paolo. História da propriedade e outros ensaios. Tradução de Luiz Ernani Fritoli e Ricardo Marcelo Fonseca. Revisão técnica de Ricardo Marcelo da Fonseca. Rio de Janeiro: Renovar, 2006. 
GROSSI, Paolo. Primeira lição sobre direito. Rio de Janeiro: Forense, 2006.

GROSSI, Paolo. Para além do subjetivismo jurídico moderno. Curitiba: Juruá, 2007.

GROSSI, Paolo. L'inaugurazione dela proprietà moderna. Napoli: Guida, 1980.

GROSSI, Paolo. Il domínio e le cose: percezione medieval e moderne dei dirittti reali. Milano: Giuffrè, 1992.

GROSSI, Paolo. La propiedad y las propiedades. Um análise histórico. Madrid: Civitas, 1992.

GROSSI, Paolo. Mitologias jurídicas da modernidade. 2. ed. Ver. E atual. Trad. Arno Dal Ri Júnior. Florianópolis: Fundação Boiteux, 2007.

HESPANHA. António Manuel. Cultura Jurídica Européia. Síntese de um Milênio. Florianópolis: Fundação Boiteux, 2005.

HESPANHA. António Manuel. Panorama histórico da cultura jurídica européia. Mem Martins: Publicações Europa-américa, 1997.

HESPANHA, António Manuel. Pluralismo Jurídico e Direito Democrático. São Paulo: Annablume, 2013.

KANT, Immanuel. Immanuel Kant - textos seletos. Tradução de Raimundo Vier e Floriano de Souza Fernandes. Petrópolis: Vozes, 1974.

KANT, Immanuel. Crítica da Razão Pura. Trad. Valério Rohden e Udo Baldur Moosburger. São Paulo: Editora Abril Cultural, 1980.

KANT, Immanuel. Crítica da Razão Prática. Trad. de Valério Rohden. $3^{a}$. edição. São Paulo: Editora Martins Fontes, 2011.

KEHL, Maria Rita. Civilização Partida. In: NOVAES, Adauto (Org.). Civilização e Barbárie. São Paulo: Companhia das Letras, 2004.

LABURTHE-TOLRA, Philippe; WARNIER, Jean-Pierre. Etnologia-Antropologia. Trad. Anna Hartmann Cavalcanti; revisão da trad., org. literária e editoração Jaime A. Clasen; revisão técnica Antônio Carlos de Souza Lima. Petrópolis: Vozes, 1997.

LAFARGUE, Paul. O Direito à Preguiça. Trad. J. Teixeira Coelho Neto. 2. ed. São Paulo: Editora Hucitec; Unesp, 1999.

LALANDE, André. Vocabulário técnico e crítico da filosofia. $2^{\mathrm{a}}$ ed. São Paulo: Martins Fontes, 1996.

LIBERATO, Ana Paula Gularte. Reforma Agrária: direito humano fundamental. Curitiba: Juruá, 2004.

LIMA, Ruy Cirne. Pequena história territorial do Brasil: sesmarias e terras devolutas. 5 ed. Goiânia: UFG, 2002.

LOCKE, John.. Trad. Magda Lopes e Marisa Lobo da Costa. Segundo Tratado sobre o Governo Civil e Outros Escritos. 2a . ed. Petrópolis: Editora Vozes, 1999. 
LOPARIC, Zeljko. Ética e finitude. São Paulo: Ed. Escuta, 2004.

LUDWIG, Celso Luiz. Paradigma da vida concreta. Texto disponibilizado pelo autor em formato eletrônico.

MARÉS, Carlos Frederico. Introdução ao Direito Socioambiental. In: LIMA, André (org.). $\mathrm{O}$ Direito para o Brasil Socioambiental. Porto Alegre: Fabris, 2002.

MARÉS, Carlos Frederico. Função Social da Propriedade. In Reforma Agrária e Meio Ambiente: teoria e prática no estado do Paraná. Claudia Sonda (Org.), Silvia Cristina Trauczynski (Org.). Curitiba: ITCG, 2010.

MARX, Karl (BARBOSA, Regis; e KOTHE, Flávio R.; trad.). O Capital: crítica da economia política. vol. 01. livro 01. tomo 02. 2 ed. São Paulo: Nova Cultural, 1985.

MARX, Karl. Prefácio à Contribuição à Crítica da Economia Política. In MARX, K. e ENGELS, F. História. Org. Florestan Fernandes. São Paulo: Ática, 1984.

MATURANA, Humberto \& VARELA, Francisco. A árvore do conhecimento: as bases biológicas da compreensão humana. $3^{\mathrm{a}}$. Ed. São Paulo: Palas Athena, 2003.

MELLO, Marco Aurélio Bezerra de. Palestra no Seminário Estadual sobre a Regularização Fundiária de Terras de Quilombo do Estado do Rio de Janeiro - realizado no dia 08 de abril de 2005 no auditório da FESUDEPERJ - Fundação Escola Superior para a Defensoria Pública do Estado do Rio de Janeiro, 2005b, mimeo, p. 2. Apud TRECCANI, Girolamo Domenico. Terras de Quilombo: caminhos e entraves do processo de titulação. Belém: Secretaria Executiva de Justiça. Programa Raízes, 2006.

MEZZAROBA, Orides (org.). Humanismo Latino e Estado no Brasil. Florianópolis: Fundação Boiteux; [Treviso]: Fondazione Cassamarca, 2003.

NOVAES, Adauto (Org.). Civilização e Barbárie. São Paulo: Companhia das Letras, 2004.

PERLINGIERI, Pietro. Perfis do Direito Civil: Introdução ao Direito Civil Constitucional. Tradução de Maria Cristina de Cicco. Rio de Janeiro: Renovar, 1999.

RAU, Virgínia. As Sesmarias Medievais Portuguesas. Lisboa: Presença, 1982.

REZENDE, Astolfo. A posse e sua Proteção. 2 vols. Livraria Acadêmica, 1937.

ROCHA, Osvaldo de Alencar. O negro e a posse da terra no Brasil. In: SOUZA FILHO, Carlos Frederico Marés de; ALFONSIN, Jacques Távora; OCHA, Osvaldo de Alencar; PRESSBURGER, T. Miguel. Negros e Índios no Cativeiro da Terra. Rio de Janeiro: Instituto Apoio Jurídico Popular e FASE, 1989, p. 45.

ROULAND, Norbert. Nos Confins do Direito. Trad. Maria Ermantina de Almeida Prado Galvão. São Paulo: Martins Fontes, 2003.

ROULAND, Norbert (Org.). Direito das minorias e dos povos autóctones. Trad. Ane Lize Spaltemberg. Brasília: UNB, 2004.

RUSSELL, Bertrand. O elogio ao ócio. Trad. Pedro Jorgensen Júnior. Rio de Janeiro: Sextante, 2002. 
SANTOS, Boaventura de Sousa. Democratizar a Democracia: os Caminhos da Democracia Participativa. Vol. 1: Reinventar a Emancipação Social: para novos manifestos. Rio de Janeiro: Civilização Brasileira, 2003.

SANTOS, Boaventura de Sousa; RODRÍGUEZ, César. Introdução: para ampliar o cânone da produção. In: SANTOS, Boaventura de Sousa (org.). Produzir para viver: os caminhos da produção não capitalista. Vol. 2: Reiventar a Emancipação Social: Para Novos Manifestos. Rio de Janeiro: Civilização Brasileira, 2002.

SANTOS, Boaventura de Sousa. Reconhecer para libertar: os caminhos do cosmopolismo multicultural. Vol. 3: Reinventar a Emancipação Social: para novos manifestos. Rio de Janeiro: Civilização Brasileira, 2003.

SANTOS, Boaventura de Sousa (et. al.). Introdução: Para ampliar o cânone da ciência: a diversidade epistemológica do mundo. In: SANTOS, Boaventura de Sousa (org.). Semear outras soluções: os caminhos da biodiversidade e dos conhecimentos rivais. Vol. 4: Reiventar a Emancipação Social: Para Novos Manifestos. Rio de Janeiro: Civilização Brasileira, 2005.

SANTOS, Boaventura de Sousa. Para um novo senso comum: a ciência, o direito e a política na transição paradigmática. Vol. I: A Crítica da Razão Indolente: contra o desperdício da experiência. 4. ed. São Paulo: Cortez Editora, 2002.

SANTOS, Boaventura de Sousa. Pela Mão de Alice: O social e o político na pós-modernidade. 9. Edição. São Paulo: Cortez, 2003.

SANTOS, Boaventura de Sousa; MENESES, Maria Paula G. de; NUNES, João Arriscado. Introdução: Para ampliar o cânone da ciência: a diversidade epistemológica do mundo. In: SANTOS, Boaventura de Sousa (org.). Semear outras soluções: os caminhos da biodiversidade e dos conhecimentos rivais. Vol. 4: Reiventar a Emancipação Social: Para Novos Manifestos. Rio de Janeiro: Civilização Brasileira, 2005.

SCHWARTZ, Stuart. Escravos, roceiros e rebeldes. Bauru (SP): EDUSC, 2001.

SILVA, Lígia Osório. Terras devolutas e latifúndio - Efeitos da Lei de 1850. Campinas: Unicamp, 1996.

SONDA, Claudia; TRAUCZYNSKI, Silvia Cristina. (Orgs.). Reforma Agrária e meio ambiente: teoria e prática no Estado do Paraná. Curitiba: ITCG, 2010.

SOUZA FILHO, Carlos Frederico Marés de. A função Social da Terra. Porto Alegre: Fabris, 2003.

SOUZA FILHO, Carlos Frederico Marés de. O Renascer dos Povos Indígenas para o Direito. Curitiba: Juruá, 2005.

SOUZA FILHO, Carlos Frederico Marés de. Os direitos invisíveis. In: OLIVEIRA, Francisco de; PAULI, Maria Célia (ORG). Os sentidos da Democracia: políticas do dissenso e hegemonia global. Rio de Janeiro: Vozes Editora, 1999.

SOUZA FILHO, Carlos Frederico Marés de. Bens Culturais e Proteção Jurídica. Porto Alegre: UE/Porto Alegre, 1997.

Revista de Sociologia, Antropologia e Cultura Jurídica | e-ISSN: 2526-0251 | Maranhão | v. 3 | n. 2 | p. 18 - 44 | Jul/Dez. 2017. 
STAUT JÚNIOR, Sérgio Said. Posse e dimensão jurídica no Brasil: recepção e reelaboração de um conceito a partir da segunda metade do século XIX ao Código de 1916. Curitiba: Juruá, 2015.

VIANA DA CRUZ, André. Perspectivas Pós-metafísicas da Hermenêutica Jurídica. In: KOZICKI, Katya e CHUEIRI, Vera Karam de (Coordenadoras). Estudos em Direito, Política e Literatura. $1^{a}$. edição. Curitiba - PR : Juruá, 2006, v.1, p. 113-126.

WEBER, Max. A Ética Protestante e o Espírito do Capitalismo. Trad. Talcott Parsons. São Paulo: Editora Martin Claret, 2004.

WOLKMER, Antonio Carlos. Pluralismo Jurídico: Fundamentos de uma nova cultura do Direito. 3. ed. (rev. e atualiz.). São Paulo: Editora Alfa Omega, 2001.

WOOD, Ellen Meiksins (SILVA, Lígia Osório; trad.). As Origens Fundiárias do Capitalismo. In: Revista Crítica Marxista, nº 10, 2000. São Paulo: Boitempo. 